\title{
Inhibition of Phenotypic and Functional Maturation of Dendritic Cells by Manassantin A
}

\author{
Jee Youn Kim ${ }^{1}$, Jong Soon Kang ${ }^{2}$, Hwan Mook Kim², Young Kook Kim², Hong Kyung Lee ${ }^{1}$, Sukgil Song ${ }^{1}$, \\ Jin Tae Hong ${ }^{1}$, Youngsoo Kim ${ }^{1}$, and Sang-Bae Han ${ }^{1, *}$ \\ ${ }^{1}$ College of Pharmacy, Chungbuk National University, Cheongju, Chungbuk 361-763, Korea \\ ${ }^{2}$ Korea Research Institute of Bioscience and Biotechnology, Ochang, Chungbuk 363-883, Korea
}

Received November 7, 2008; Accepted February 13, 2009

\begin{abstract}
Manassantin A (MSA) inhibits nitric oxide production by macrophages through the inhibition of NF- $\kappa$ B activation, but the effect of MSA on dendritic cells has not been elucidated yet. Here we investigated the inhibitory effects of MSA on immune functions of dendritic cells (DCs). MSA inhibited lipopolysaccharide (LPS)-induced phenotypic maturation of DCs, which was proved by the decreased expression of CD40, CD80, CD86, MHC-I, and MHC-II. MSA also inhibited functional maturation of DCs, that is, decreased the gene expression of IL-12, IL- $1 \beta$, TNF- $\alpha$, and IFN- $\alpha / \beta$; enhanced antigen capture capacity of DCs; and impaired induction of allogenic T cell activation. As a mechanism of action, MSA inhibited LPS-induced activation of $\mathrm{NF}-\kappa \mathrm{B}, \mathrm{ERK}, \mathrm{p} 38$, and JNK, which played pivotal roles in toll-like receptor 4-mediated DC maturation. Collectively, these results suggested that MSA might be used for the treatment of DC-related immune diseases.
\end{abstract}

Keywords: manassantin A, dendritic cell, maturation, mitogen-activated protein kinase, NF- $\kappa \mathrm{B}$

\section{Introduction}

Dendritic cells (DCs) are antigen-presenting cells that are believed to possess immune sentinel properties. Being the most potent antigen presenting cells in vitro and in vivo, they play a key role in the initiation of the immune response and are considered promising tools and targets for immunotherapy $(1-3)$. Immature DCs capture and process exogenous agents within peripheral tissues, in which they begin to mature. In tissues, DCs are equipped to capture antigens and produce large numbers of immunogenic MHC-peptide complexes. In the presence of maturation-inducing stimuli such as inflammatory cytokines or stimulation via CD40 ligand or lipopolysaccharide (LPS), DCs up-regulate adhesion and co-stimulatory molecules to become more potent stimulators of $\mathrm{T}$ cell immunity $(4,5)$. The three major mitogen-activated protein kinases (MAPKs), the extracellular signal-regulated kinases (ERK), the c-Jun Nterminal kinases (JNK), and p38 MAPK are activated in

*Corresponding author. shan@chungbuk.ac.kr Published online in J-STAGE on April 7, 2009 (in advance) doi: 10.1254/jphs.08299FP
DCs on maturation induced by LPS or TNF- $\alpha$. Another intracellular component involved in DC maturation is the transcription factor NF- $\kappa \mathrm{B}(6-9)$.

Saururus chinensis (Saururaceae) is a perennial herb distributed in Japan, China, and Korea; and it has been used in folk medicine to treat edema and gonorrhea and also as a uretic in Korean traditional medicine. Manassantin A (MSA), a dineolignan isolated from Saururus cernuus, was known to inhibit NF- $\kappa$ B activation and nitric oxide production in macrophages (10, 11). In addition, MSA inhibited hypoxia-inducible factor- $1 \alpha(\mathrm{HIF}-1 \alpha)$ by blocking protein accumulation without affecting mRNA levels. HIF- $1 \alpha$ represented an important tumor-selective therapeutic target for solid tumors and over-expression of HIF-1 $\alpha$ was a negative indicator for tumor treatment outcome. Therefore, MSA might be considered as a valuable candidate for the intervention of a pathological condition such as inflammation and cancer.

Here we investigated the suppressive activity of MSA on DCs, which were responsible for the initiation of $\mathrm{T}$ cell-mediated immunity. In vitro pharmacological modifications of maturation and function of DCs might be useful to optimize their capacity to modulate T cell- 
mediated immune responses, thus offering new opportunities to develop immunotherapeutic protocols. We found that MSA inhibited phenotypic and functional DC maturation stimulated with LPS. The inhibition was correlated with blockade of the MAPKs and NF- $\kappa$ B pathway.

\section{Materials and Methods}

\section{Materials}

Female C57BL/ 6 and BALB/c mice $(6-8$ weeks of age) were obtained from Korea Research Institute of Bioscience and Biotechnology (Chungbuk, Korea). Mice were housed in specific pathogen-free conditions at $21^{\circ} \mathrm{C}-24^{\circ} \mathrm{C}$ and $40 \%-60 \%$ relative humidity under a 12-h light/dark cycle. All animals were acclimatized for at least 1 week prior to the experiments. The experimental procedures used in this study were approved by the KRIBB Animal Experimentation Ethics Committee. Anti-mouse antibodies against CD11c, CD40, CD80, CD86, MHC-I, and MHC-II were purchased from Invitrogen Corporation (Carlsbad, CA, USA). ERK, p38, and JNK were purchased from Cell Signaling (Danvers, MA, USA).

\section{Isolation of mouse DCs}

DCs were generated from bone marrow (BM) cells obtained from 6 - 7-week-old female mice (12). Briefly, BM cells were flushed out from femurs and tibias. After lysing red blood cells, whole BM cells $\left(2 \times 10^{5}\right.$ cells $\left./ \mathrm{ml}\right)$ were cultured in $100-\mathrm{mm}^{2}$ culture dishes in $10 \mathrm{ml} /$ dish of complete medium containing $2 \mathrm{ng} / \mathrm{ml} \mathrm{GM-CSF}$. On culture day 3 , another $10 \mathrm{ml}$ of fresh complete medium containing $2 \mathrm{ng} / \mathrm{ml}$ of GM-CSF was added, and on day 6 , half of the medium was changed. On day 8 , non-adherent and loosely adherent DCs were harvested by vigorous pipetting and used as immature DCs (iDCs). iDCs recovered from these cultures were generally $>85 \% \mathrm{CD} 11 \mathrm{c}^{+}$and $\mathrm{MHC}-\mathrm{II}^{\text {med-high }}, \mathrm{CD} 80^{\mathrm{med}}$, and CD $86^{\text {low-med }}$.

\section{Phenotype analysis}

Phenotypic maturation of DCs was analyzed by flow cytometry (12). Cell staining was performed using a combination of FITC-conjugated anti-CD80, anti-CD86, or anti-MHC and PE-conjugated CD11c antibody. Cells were analyzed using a FACSCalibur flow cytometer (BD Biosciences, San Jose, CA, USA), and data were analyzed using WinMDI software (Scripps, La Jolla, CA, USA). Forward and side scatter parameters were used to gate live cells. Cell viability was examined by the propidium iodide (PI) nuclear staining method. Cells were stained with $1 \mu \mathrm{g} / \mathrm{ml}$ of PI and analyzed with the
FACSCalibur flow cytometer. Cells stained with PI were considered as dead cells (13).

\section{Endocytosis assay}

To analysis the endocytosis of DCs, $4 \times 10^{5}$ DCs were incubated at $37^{\circ} \mathrm{C}$ for $1 \mathrm{~h}$ with $0.7 \mathrm{mg} / \mathrm{ml} \mathrm{FITC}$-dextran (42,000 Da; Sigma-Aldrich, St. Louis, MO, USA). After incubation, cells were washed twice with cold washing buffer (PBS containing 0.5\% BSA) and stained using PE-conjugated anti-CD11c antibody. Double stained DCs were analyzed by flow cytometry. In addition, parallel experiments were performed at $4^{\circ} \mathrm{C}$ to determine the nonspecific binding of FITC-dextran to DCs $(14,15)$.

\section{Measurement of secreted IFN- $\gamma$ and IL-2}

Levels of IFN- $\gamma$ and IL-2 in culture supernatants were measured using commercial immunoassay kits (R\&D Systems, Minneapolis, MN, USA).

Reverse transcription-polymerase chain reaction (RTPCR)

Total RNA was isolated using TRIZOL ${ }^{\mathrm{TM}}$ Reagent (Molecular Research Center, Cincinnati, OH, USA). For RT-PCR, single-strand cDNA was synthesized from $2 \mu \mathrm{g}$ total RNA. The primer sequences used were as follows: IL-12, sense 5'-AGA GGT GGA CTG GAC TCC CGA-3', antisense 5'-TTT GGT GCT TCA CAC TTC AG-3'; TNF- $\alpha$, sense, 5'-AGG TTC TGT CCC TTT CAC TCA CTG-3', antisense, 5'-AGAGAA CCT GGG AGT AGA CAA GGT A-3'; IL-1 $\beta$, sense, 5'-ATG GCA ATG TTC CTG AAC TCA ACT-3', antisense, 5'-CAG GAC AGG TAT AGA TTC TTT CCT TT-3'; IFN- $\alpha$, sense, 5'-TCT GAT GCA GCA GGT GGG-3', antisense, 5'-AGG GCT CTC CAG AYT TCT GCT CTG-3'; IFN$\beta$, sense, 5'-CCA CAG CCC TCT CCA TCA ACT ATA AGC-3', antisense, 5'-AGC TCT TCA ACT GGA GAG CAG TTG AGG-3'; $\beta$-actin, sense 5'-TGG AAT CCT GTG GCA TCC ATG AAAC-3', and antisense 5'-TAA AAC GCA GCT CAG TAA CAG TCCG-3'. PCR products were fractionated on $1 \%$ agarose gels and stained with $5 \mu \mathrm{g} / \mathrm{ml}$ ethidium bromide.

\section{Western blots}

Cell lysates were prepared as previously described (16). Detergent-insoluble materials were removed, and equal amounts of protein were fractionated by $10 \%$ SDS-PAGE and transferred to pure nitrocellulose. Membranes were blocked with 5\% BSA in Tween 20 plus TBS (TTBS) for $1 \mathrm{~h}$ and then incubated with an appropriate dilution of primary antibody in 5\% BSA (in TTBS) for $2 \mathrm{~h}$. Blots were incubated with biotinylated antibody for $1 \mathrm{~h}$ and further incubated with streptoavidin conjugated to HRP for $1 \mathrm{~h}$. Signals were detected by 
enhanced chemiluminescence (Amersham Pharmacia Biotech, Piscataway, NJ, USA).

\section{Mixed leukocyte reaction (MLR)}

Responder $\mathrm{T}$ cells were purified from the spleen of $\mathrm{BALB} / \mathrm{c}$ mice by negative depletion using biotinylated antibodies for B220, GR-1, and CD11c (BD Pharmingen, San Diego, CA, USA) and Dynabeads M-280 streptoavidin (Invitrogen, Dynal, Inc., Oslo, Norway), as previously described (17). Purity was typically more than $90 \%$. DCs were generated from the BM cells of C57BL $/ 6$ mice and were treated with $40 \mu \mathrm{g} / \mathrm{ml}$ mitomycin C (MMC) for $1 \mathrm{~h}$. MMC-treated DCs were added in graded doses to $1 \times 10^{5} \mathrm{~T}$ cells in U-bottom 96well plates. Allogenic $\mathrm{T}$ cells were pulsed with ${ }^{3} \mathrm{H}$ thymidine (113 Ci/nmol; NEN, Boston, MA, USA) at a concentration of $1 \mu \mathrm{Ci} /$ well for the last $18 \mathrm{~h}$ and harvested on day 5 using an automated cell harvester (Innotech, Dottikon, Switzerland). The amount of ${ }^{3} \mathrm{H}-$ thymidine incorporated into cells was measured using a Wallac Microbeta scintillation counter (Wallac, Turku, Finland) (12).

\section{Statistics}

Data represent the mean \pm S.D. of more than three samples and all experiments were performed more than three times. S.D. were calculated by the Student's $t$-test and $P$ values were calculated by ANOVA software (GraphPad Software, La Jolla, CA, USA).

\section{Results}

Immature DCs were generated from BM precursors by using $2 \mathrm{ng} / \mathrm{ml}$ of GM-CSF. On day 8 of culture, non-adherent and loosely adherent cells, that is, immature DCs were harvested from cultures. An analysis of cell surface makers showed that more than $85 \%$ of cells were $\mathrm{CD} 11 \mathrm{c}+$, but not $\mathrm{CD} 3+$ or B220+ (data not shown). Immature DCs were treated with LPS for $24 \mathrm{~h}$ to induce maturation. First, we verified that MSA at concentrations used in this study had no or minimal effect on the viability of DCs (Fig. 1). MSA at concentrations from 1 to $1000 \mathrm{ng} / \mathrm{ml}$ showed no toxicity on immature and LPS-treated mature DCs, which was proved by the PI staining method. In the following experiments, we focused on the effect of MSA at non-toxic concentrations on the process of LPS-induced DC maturation.

\section{MSA inhibits the phenotypic maturation of DCs}

To investigate whether MSA could affect DC maturation, we treated DCs with LPS and MSA for $24 \mathrm{~h}$. Although the mean fluorescence intensity (MFI) of cell surface molecules was quiet low in immature DCs,

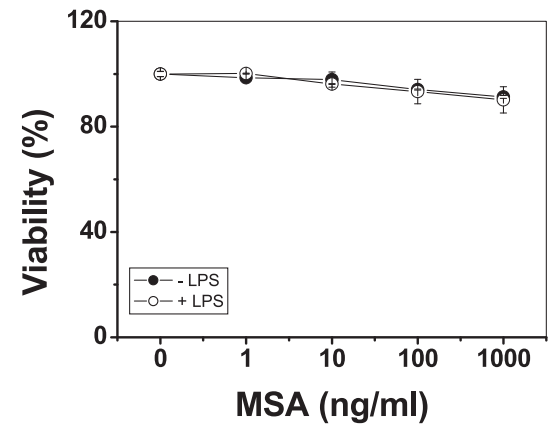

Fig. 1. Cytotoxicity of MSA. Immature DCs (iDCs) were generated from mouse BM cells by treating them with $2 \mathrm{ng} / \mathrm{ml}$ of GM-CSF for 8 days. iDCs were treated with MSA alone (- LPS) or MSA plus LPS (+ LPS) for $24 \mathrm{~h}$. Non-adherent and loosely adherent cells were harvested and stained with $1 \mu \mathrm{g} / \mathrm{ml}$ of propidium iodide (PI). Cell viability (\%) was examined with a flow cytometer and PI-stained cells were considered to be dead cells. Results are presented as mean \pm S.D.

LPS treatment was accompanied by a marked upregulation of CD80 (Fig. 2A), CD86 (Fig. 2B), MHC-I (Fig. 2C), MHC-II (Fig. 2D), and CD40 (Fig. 2E), which are known as surface markers of mature DCs. MSA dose-dependently decreased their expressions (Fig. 2). This compound had only a slight effect on the expression of CD80 (Fig. 3A), CD86 (Fig. 3B), MHC-I (Fig. 3C), and MHC-II (Fig. 3D) of LPS-untreated immature DCs.

To investigate whether MSA selectively inhibited DC maturation induced by LPS, we examined the effect of MSA on DC maturation induced by Poly (I:C), a TLR3 agonist, and zymosan, a TLR2 agonist. As shown in Fig. 4, MSA dose-dependently inhibited up-regulation of CD86 in DCs treated with poly (I:C) (Fig. 4A) or zymosan (Fig. 4B). These results demonstrated that MSA decreased the phenotypic maturation of DCs induced by LPS, poly (I:C), and zymosan.

MSA reduces the cytokine gene expression by DCs triggered by LPS stimulation

DC produces many cytokines during maturation. To evaluate the effect of MSA on cytokine production by LPS-stimulated DC, we exposed immature DCs to LPS in the presence or absence of MSA for $4 \mathrm{~h}$ and measured the cytokine gene expression by RT-PCR. As shown in Fig. 5: A and B, mRNA expressions of IL-12, TNF- $\alpha$, IL- $1 \beta$, IFN- $\alpha$, and IFN- $\beta$ markedly increased upon exposure of DCs to LPS; and they were decreased by the treatment of MSA. These results indicated that exposure to MSA impaired the ability of DC to induce gene expression of IL-12 and pro-inflammatory cytokines. The results suggested that MSA suppressed the functional maturation of LPS-stimulated DC. 
A

UN

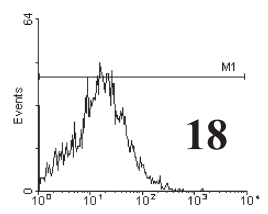

LPS

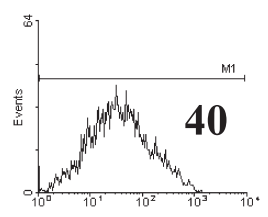

1

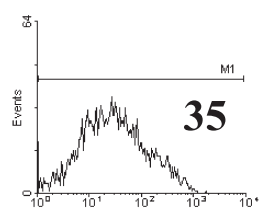

10

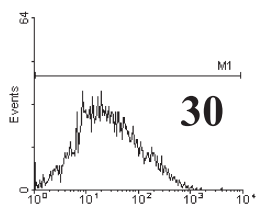

100

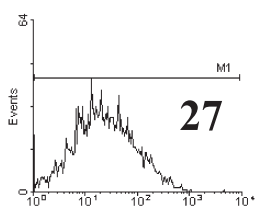

1000

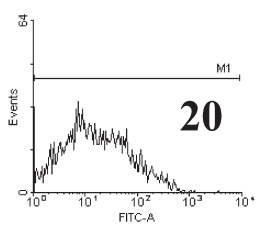

B
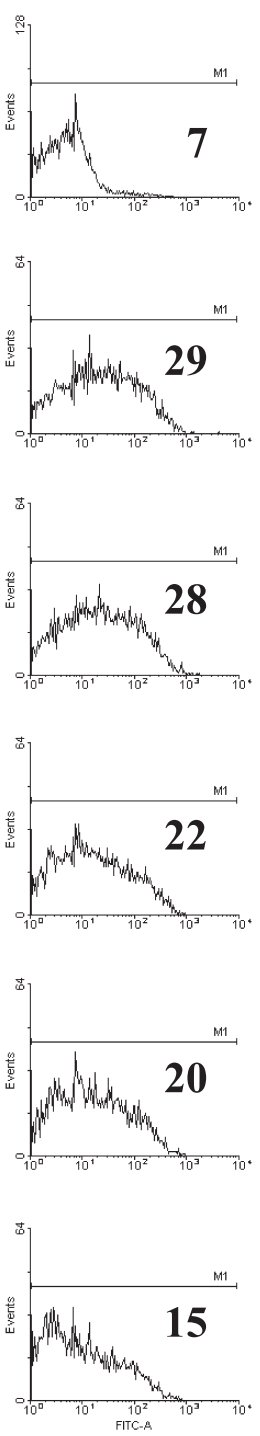
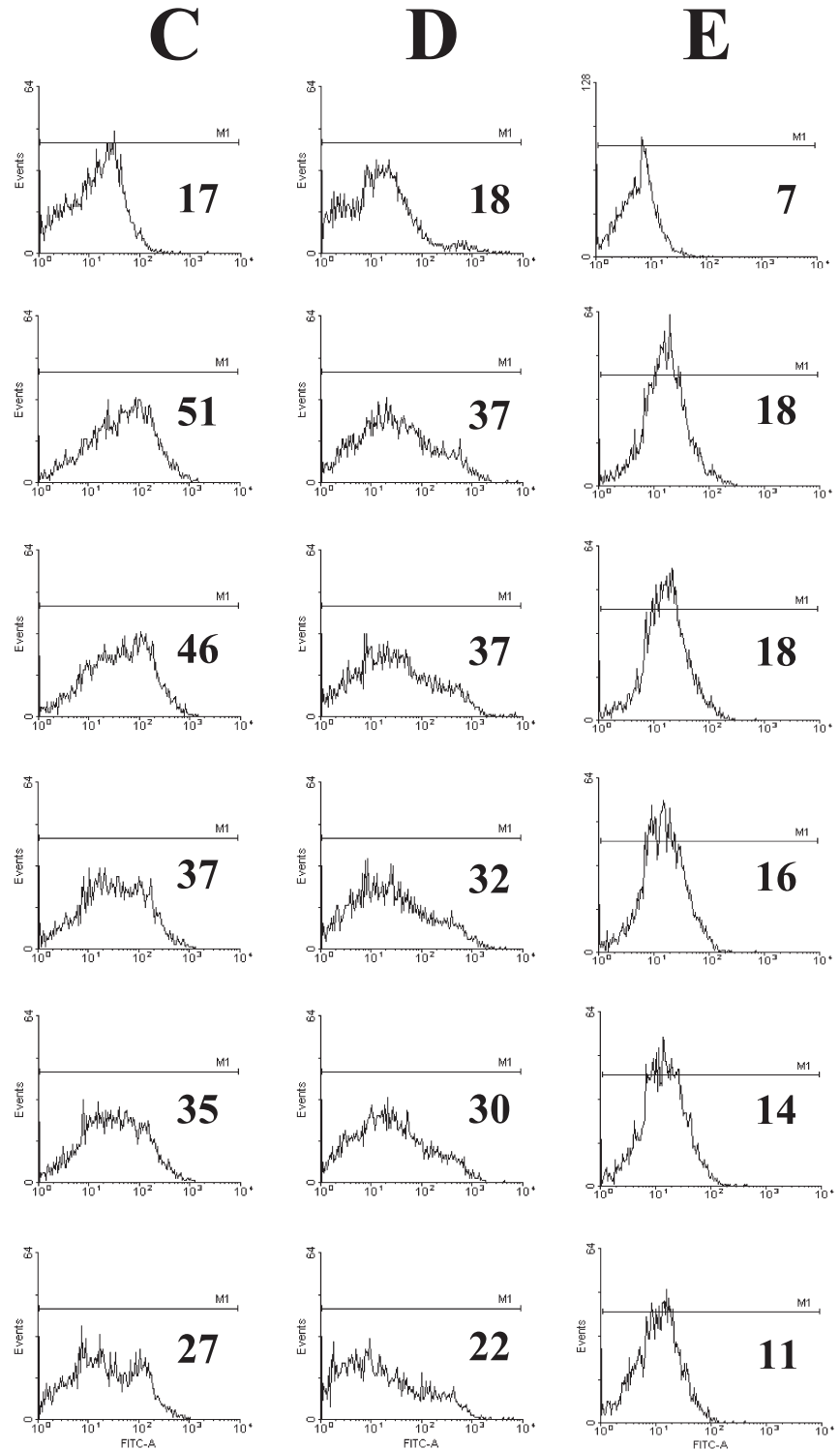

Fig. 2. Inhibition of LPS-induced phenotypic maturation of DCs by MSA. Immature DCs (iDCs) were generated from mouse BM cells by treating them with $2 \mathrm{ng} / \mathrm{ml}$ of GM-CSF for 8 days (designated as UN) and further treated with $1 \mu \mathrm{g} / \mathrm{ml}$ of LPS and/or MSA for $24 \mathrm{~h}$. Non-adherent and loosely adherent cells were harvested and stained with two Abs, i.e., PE-conjugated CD11c Ab plus FITC-conjugated Abs to CD80 (A), CD86 (B), MHC-I (C), MHC-II (D), and CD40 (E). CD11c-PE was used to gate DCs. Histograms and mean fluorescence intensities (MFI) are shown. Results are representative of more than three separate experiments.

MSA affects the endocytotic activity of DCs

Immature DCs show a potent ability to uptake external molecules, essentially via two main mechanisms: a receptor-mediated endocytosis and a fluidphase endocytosis (macropinocytosis). However, mature DCs showed lowered endocytosis. To examine the effect of MSA on endocytosis of DCs, fluorescent marker dextran-FITC, which was mainly taken up via the mannose receptor, was used. After incubation of BMderived DCs with MSA in the presence of LPS, dextranFITC was added to the culture medium. We found that
MSA-treated DC exhibited a higher degree of endocytotic capacity for dextran-FITC (Fig. 6A). These results showed that MSA inhibited functional maturation of DCs. Parallel experiments were performed at $4^{\circ} \mathrm{C}$ to examine nonspecific binding/uptake of dextran-FITC to BM-derived DCs (Fig. 6B).

MSA-treated DCs show decreased allogenic T cell proliferation

Alloactivation of $\mathrm{T}$ cells was another parameter of DC maturation. Compared with immature DCs, mature 
A $\quad$ B $\quad$ C $\quad$ D

$\mathbf{U N}$
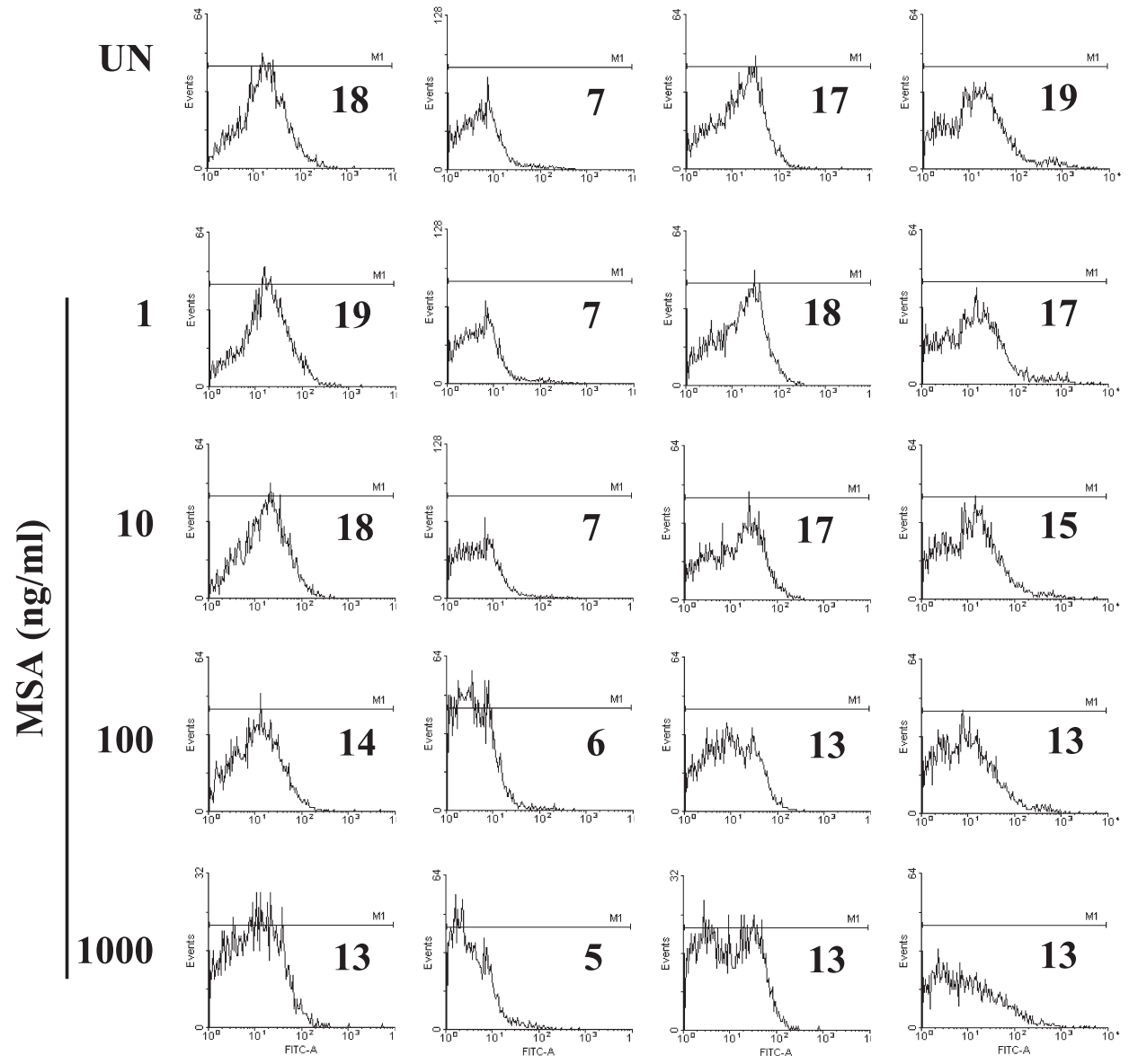

Fig. 3. Effect of MSA on immature DCs. Immature DCs (iDCs) were generated from mouse BM cells by treating them with $2 \mathrm{ng} / \mathrm{ml}$ of GM-CSF for 8 days (designated as $\mathrm{UN}$ ) and further treated MSA alone for $24 \mathrm{~h}$. Non-adherent and loosely adherent cells were harvested and stained with two Abs, i.e., PE-conjugated CD11c Ab plus FITC-conjugated Abs to CD80 (A), CD86 (B), MHC-I (C), and MHC-II (D). CD11c-PE was used to gate DCs. Histograms and mean fluorescence intensities (MFI) are shown. Results are representative of more than three separate experiments.

DCs could strongly activate $\mathrm{T}$ cells to proliferate and to produce cytokines. To examine the effect of MSA on functional maturation of DCs, we induced a mixed lymphocyte response by using DCs matured with LPS in the presence or absence of MSA. As shown in Fig. 7A, T cells incubated with immature DCs showed no proliferation. However, $\mathrm{T}$ cells incubated with LPS-treated mature DCs showed enhanced proliferation, and it was inhibited by treating DCs with MSA. Immature DCs could not activate T cells to produce IFN- $\gamma$ (Fig. 7B) and IL-2 (Fig. 7C), which was not changed by MSA treatment. However, LPS-treated mature DCs could strongly activate $\mathrm{T}$ cells to produce these cytokines, and MSAtreated DCs showed low capacity for $\mathrm{T}$ cells to produce IFN- $\gamma$ (Fig. 7B) and IL-2 (Fig. 7C). Overall, these results suggested that MSA efficiently inhibited the functional and phenotypic maturation of DCs.
MSA inhibits the TLR4-downstream signaling pathways in $D C s$

LPS could induce DC maturation through TLR4 and its downstream signaling pathways such as MAPK and $\mathrm{NF}-\kappa \mathrm{B}$ signalings. To investigate the effect of MSA on DC maturation at the molecular level, we performed Western blotting to detect the level of phosphorylation of MAPKs and the NF- $\kappa \mathrm{B}$ complex. As shown in Fig. 8A, basal levels of phosphorylated p38, ERK, and JNK MAPKs in immature DCs were very low. However, upon exposure to LPS, we observed a profound increase in phosphorylation of MAPKs over the basal levels in mature DCs. MSA dose-dependently decreased the LPSinduced up-regulation of p-p38, p-ERK, and p-JNK.

When we examined the nuclear amount of NF- $\kappa \mathrm{B}$ p50 and p65 subunit, their basal levels in immature DCs were quite low (Fig. 8B). Upon exposure of DCs to LPS, 
A

\section{UN}

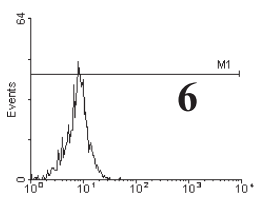

\section{Activators}

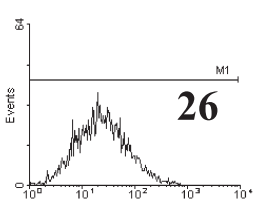

1

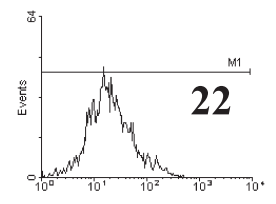

10

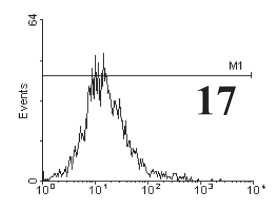

100

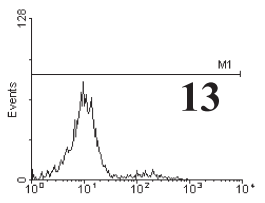

1000

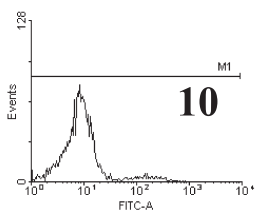

B
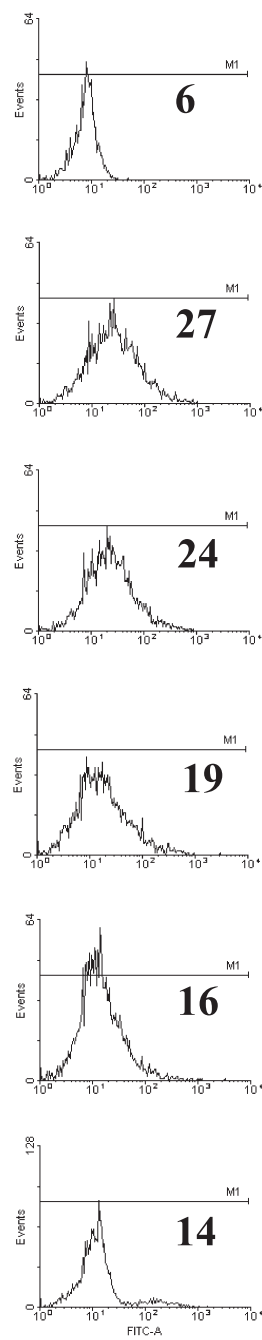

Fig. 4. Inhibition of poly (I:C)- or zymosan-induced phenotypic maturation of DCs by MSA. Immature DCs (iDCs) were generated from mouse BM cells by treating them with $2 \mathrm{ng} / \mathrm{ml}$ of GM-CSF for 8 days (designated as $\mathrm{UN}$ ) and further treated with one of two different activators: $50 \mu \mathrm{g} / \mathrm{ml}$ of poly (I:C) (A) or $5 \mu \mathrm{g} / \mathrm{ml}$ of zymosan (B). MSA $(1-1000 \mathrm{ng} / \mathrm{ml})$ was added. After $24 \mathrm{~h}$, nonadherent and loosely adherent cells were harvested and stained with PE-conjugated CD11c Ab plus FITC-conjugated CD86 Ab. CD11cPE was used to gate DCs. Histograms and mean fluorescence intensities (MFI) are shown. Results are representative of more than three separate experiments.

we observed the increase of the nuclear amount of the NF- $\kappa \mathrm{B}$ p50 and p65 subunit, which was blocked by MSA treatment. The nuclear translocation of NF- $\kappa \mathrm{B}$ complex is preceded by the degradation of cytoplasmic $\mathrm{I} \kappa \mathrm{B} \alpha$ and $\mathrm{I} \kappa \mathrm{B} \beta$. To determine whether the prevention of LPS-induced NF- $\kappa$ B nuclear translocation by MSA was due to the inhibition of $\mathrm{I} \kappa \mathrm{B}$ degradation, we examined cytosolic levels of $\mathrm{I} \kappa \mathrm{B} \alpha$ and $\mathrm{I} \kappa \mathrm{B} \beta$. As shown in Fig. $8 \mathrm{C}$, upon exposure of DCs to LPS, cytosolic $\mathrm{I} \kappa \mathrm{B} \alpha$ and $\mathrm{I} \kappa \mathrm{B} \beta$
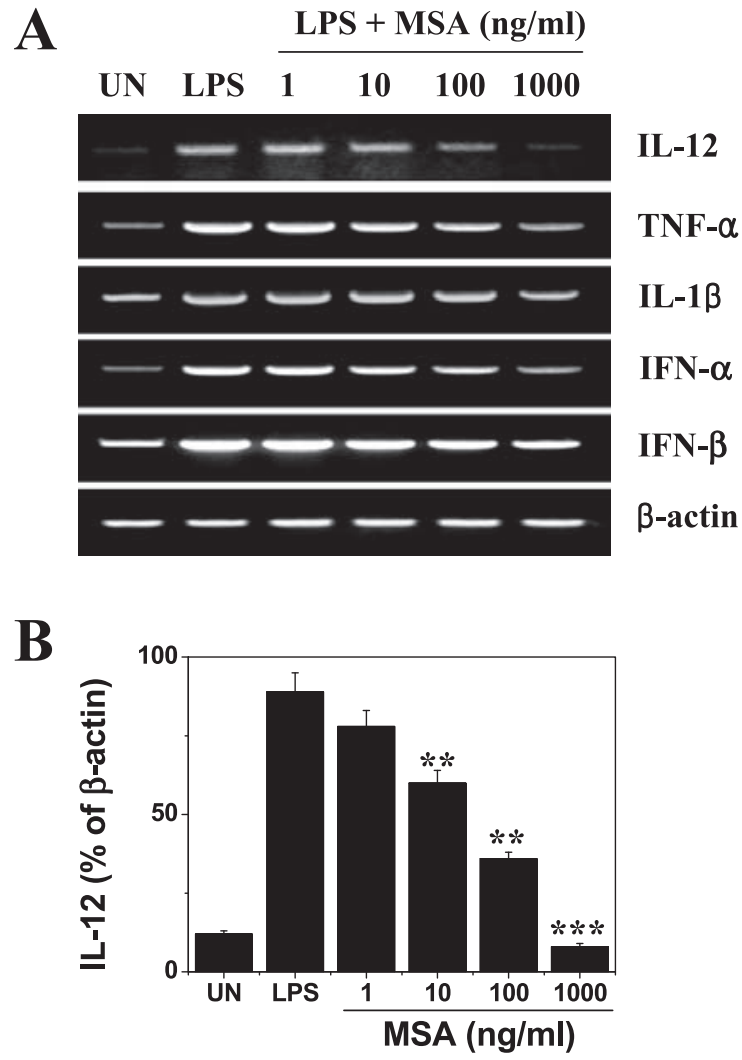

Fig. 5. Inhibition of cytokine gene expression of DCs by MSA. iDCs were generated from mouse BM cells by treating them with $2 \mathrm{ng} / \mathrm{ml}$ of GM-CSF for 8 days (designated as UN) and further treated with $1 \mu \mathrm{g} / \mathrm{ml}$ LPS in the presence or absence of MSA for $4 \mathrm{~h}$. The mRNA of IL-12p70, TNF- $\alpha$, IL- $1 \beta$, IFN- $\alpha$, and IFN- $\beta$ were detected using RT-PCR. Results are representative of more than three separate experiments (A). Band areas were analyzed using an image analysis system (ImageJ; National Institute of Health, Bethesda, MD, USA) and data were presented as ratios versus $\beta$-actin. Significance was determined using the ANOVA test vs. UN $(* * P<0.01$, $* * * P<0.001)$.

were degraded within $15-30 \mathrm{~min}$, and thereafter, their levels increased. However, MSA markedly blocked the degradation of $\mathrm{I} \kappa \mathrm{B} \alpha$ and $\mathrm{I} \kappa \mathrm{B} \beta$. These results suggested that MSA could inhibit LPS-induced DC maturation via blocking the activation of MAPKs and NF- $\kappa \mathrm{B}$ signalings.

\section{Discussion}

Recent progress in DC biology has suggested that DCs play critical roles in various diseases. In the murine system, host residual DCs were shown to be essential in the pathophysiology of graft versus host disease (GVHD) after allogeneic BM transplantation (18). Suppression of DC function may efficiently control the specific immune response since DC has the unique property to activate naïve $\mathrm{T}$ cells and are required for the induction of a primary response. It has been shown 


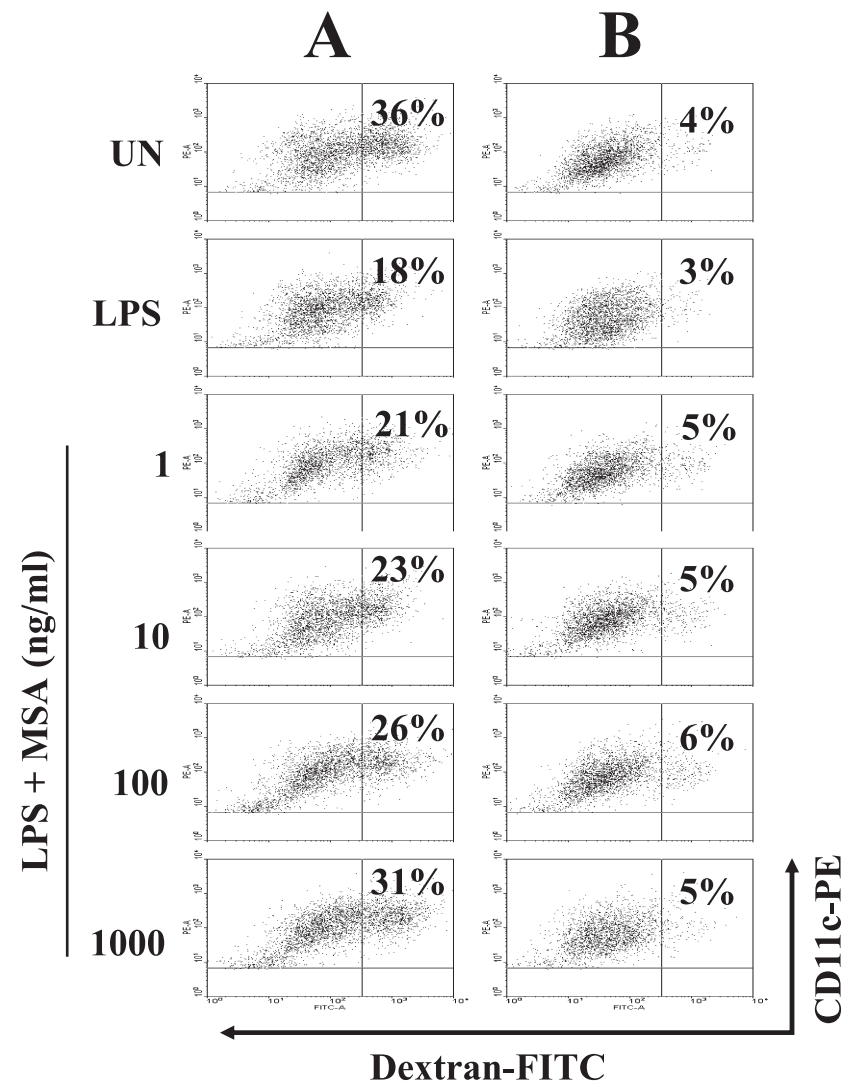

Fig. 6. Effect of MSA on endocytosis of DCs. iDCs were generated from mouse BM cells by treating them with $2 \mathrm{ng} / \mathrm{ml}$ of GM-CSF for 8 days (designated as $\mathrm{UN}$ ) and further treated with $1 \mu \mathrm{g} / \mathrm{ml}$ LPS in the presence or absence of MSA for $24 \mathrm{~h}$. Non-adherent and loosely adherent cells were harvested and treated with $0.7 \mathrm{mg} / \mathrm{ml}$ of dextranFITC for $1 \mathrm{~h}$ at $37^{\circ} \mathrm{C}(\mathrm{A})$. After washing, DCs were stained with PE-conjugated anti-CD11c Ab and double-stained DCs were analyzed by flow cytometry. Parallel experiments were performed at $4{ }^{\circ} \mathrm{C}$ to examine nonspecific binding of dextran-FITC (B). Results are representative of more than three separate experiments.

to have anti-inflammatory and immunosuppressive activities by its inhibitory effect on T cells. DCs play a major role in the initiation of $\mathrm{T}$ cell-mediated immunity by its unique capability of stimulating naïve T cells. In a recent study, the investigators showed that selective recruitment of $\mathrm{CD} 11 \mathrm{c}^{+} \mathrm{DCs}$ from peripheral blood to salivary glands and the subsequent induction of Th1 polarization might be crucial steps in the genesis of primary Sjögren's syndrome (19). Furthermore, another study implicated the pivotal roles of IFN- $\alpha$-producing plasmacytoid cells (CD11 $\left.\mathrm{c}^{-} \mathrm{DCs}\right)$ in lupus erythematosus $(20,21)$. Some immunosuppressive agents such cyclosporine A (CsA), glucocorticoids as well as 1,25dihydroxyvitamin $\mathrm{D}_{3}$, are able to impair the differentiation, maturation, and/or function of DCs, perhaps via distinct pathways $(22,23)$. Several studies have demonstrated recently that CsA affected the biological pro-
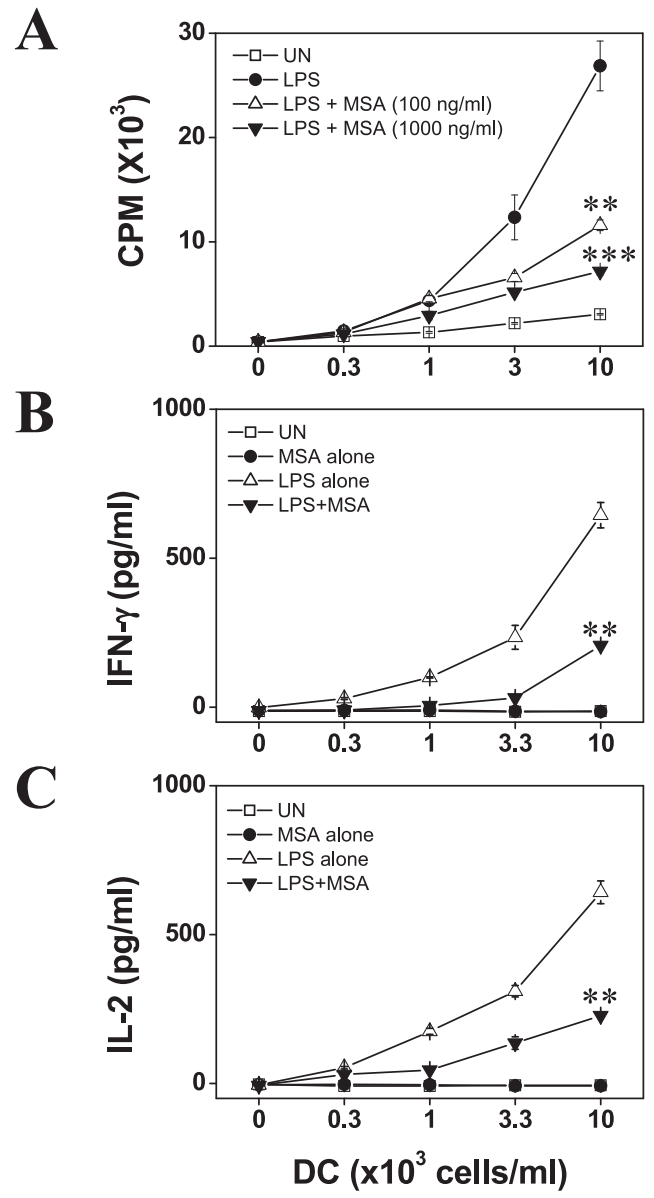

Fig. 7. Inhibition of the allo-stimulation activity of DCs by MSA. iDCs were generated from mouse BM cells by treating them with $2 \mathrm{ng} / \mathrm{ml}$ of GM-CSF for 8 days (designated as UN) and further activated with $1 \mu \mathrm{g} / \mathrm{ml}$ of LPS and/or MSA for $24 \mathrm{~h}$. Non-adherent and loosely adherent cells were harvested and treated with $40 \mu \mathrm{g} / \mathrm{ml}$ mitomycin C (MMC) for $1 \mathrm{~h}$. MMC-treated DCs were added in graded doses to $1 \times 10^{5} \mathrm{~T}$ cells purified from BALB/c mice. After 5 days of culture, cells were labeled with ${ }^{3} \mathrm{H}$-thymidine and harvested using an automated cell harvester (A). Culture medium was collected $24 \mathrm{~h}$ after mixing DCs, and T cells and IFN- $\gamma$ (B) and IL-2 (C) levels were measured by using ELISA kits (R\&D Systems, Minneapolis, MN, USA). Significance was determined by the ANOVA test versus $\mathrm{UN}(* * P<0.01, * * * P<0.001)$.

perties of DCs. For example, murine Langerhans cells and BM-derived DCs showed down-regulation of CD40 and B7 in the presence of CsA $(24,25)$.

We found in this study that MSA inhibited the phenotypic and functional maturation of DCs. MSA-treated DC showed an important modification in membrane phenotype. During DC differentiation from precursors, two major stages can be identified: 1) an immature stage characterized by a high efficiency in taking up and processing antigens; and 2) a mature stage characterized by the loss of antigen uptake capacity and migration to regional lymph nodes where DC exert their function 


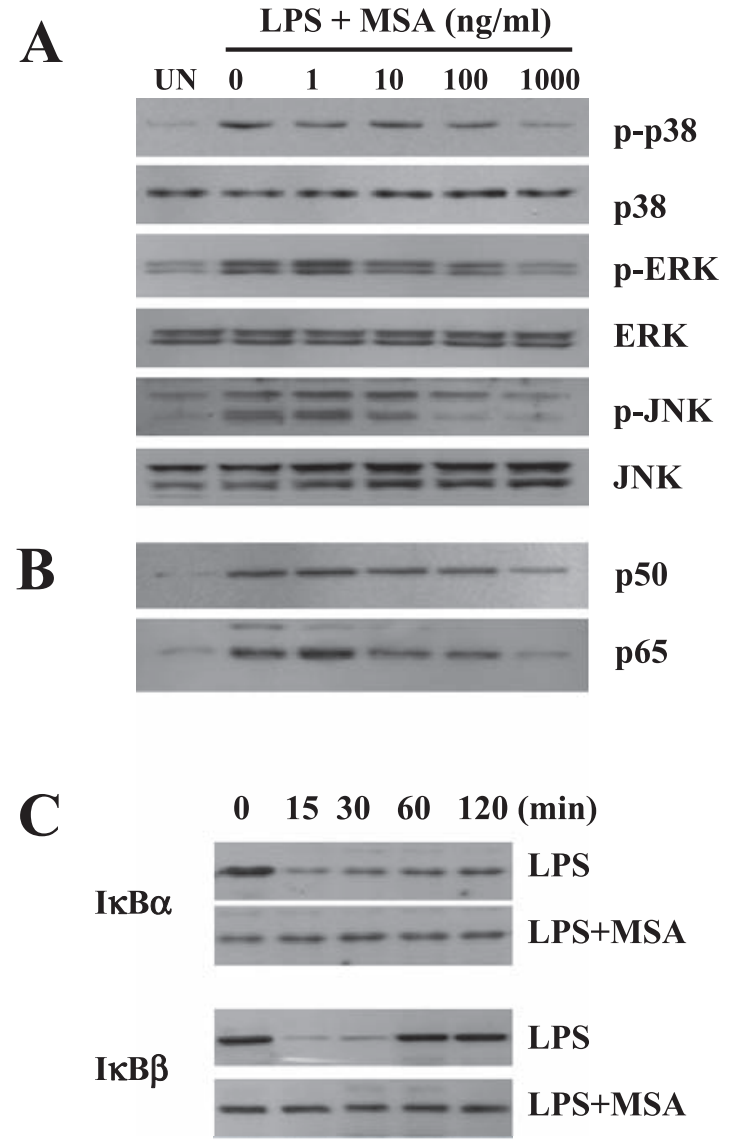

Fig. 8. Inhibition of MAPK and NF- $\kappa$ B activation by MSA. iDCs were generated from mouse BM cells by treating them with $2 \mathrm{ng} / \mathrm{ml}$ of GM-CSF for 8 days (designated as $\mathrm{UN}$ ) and were then further activated with LPS $(1 \mu \mathrm{g} / \mathrm{ml})$ and/or MSA for $15 \mathrm{~min}$. Phosphorylated-ERK, -JNK, and -p38 were detected by immunoblotting using specific antibodies (A). iDCs were incubated with LPS and/or MSA for $15 \mathrm{~min}$. Nuclear extracts were blotted with anti-p50 and anti-p-65 antibody (B). iDCs were incubated with LPS and/or MSA for 15 $120 \mathrm{~min}$, and total cell extracts were blotted with anti- $\mathrm{I} \kappa \mathrm{B} \alpha$ and anti$\mathrm{I} \kappa \mathrm{B} \beta$ antibodies (C). Results are representative of more than three separate experiments.

of potent APC (1, 3, 26-28). Results shown here demonstrated that MSA inhibited the augmented surface expression of CD40, CD80, CD86, MHC-I, and MHC-II induced by LPS in DCs, whereas endocytotic capacity of MSA-treated DC was profoundly increased. Fewer CD40 molecules on the DCs could result in diminished presentation of antigen and reduced production of cytokine and, as a consequence, lacked CD80 and CD86 up-regulation (29). Furthermore, MSA inhibited cytokine production by LPS-stimulated DC, which might have profound consequences for T cell activation. IL-12 affected $\mathrm{T}$ helper 1 (Th1) cell function by inducing secretion of IFN- $\gamma$ by T cells and NK cells (30). Inflammatory cytokines produced by DCs induce the changes required for DC maturation and migration from the periphery to the lymph nodes. The presence of inflammatory cytokines also leads to up-regulation of adhesion molecules by the endothelium, and these molecules contribute to the recruitment of monocytes and other cell types to inflamed tissue (31). This indicates that MSA down-regulates inflammation and impairs Th1 responses. MSA could further impair DC functions by inhibiting DC maturation. One major criterion for DC maturation in vitro is the high MLR stimulation (32). We found that MSA down-regulated expression of DC surface costimulatory molecules and, therefore, inhibited DC maturation and consequent MLR activity in MSAtreated $\mathrm{mDC}$. In addition, it has been suggested that stimulation of MLR by $\mathrm{mDC}$ also requires CD40 and CD40L interaction (33); therefore, down-regulation of CD40 on MSA-treated DC could also play an important role in the impairment of DC functional maturation. These results suggested that MSA could inhibit phenotypic and functional maturation of DCs induced by LPS. We also showed that MSA could inhibit poly (I:C)- and zymosan-induced maturation of DCs. These data might show that MSA inhibited DC maturation by blocking common intracellular signaling pathways from TLR2 for zymosan, TLR4 for LPS, and TLR3 for poly (I:C).

How did MSA inhibit DC maturation? In order to provide possible clues, we examined TLR4-related downstream signalings. Signaling pathways that seem to play a major role in DC maturation are the NF- $\kappa \mathrm{B}$ and MAPKs pathway $(6,7,34)$. Upon TLR4 activation, Toll/IL-1 receptor (TIR) domain efficiently recruits several TIR-containing intracellular adaptor proteins including myeloid differentiation primary-response gene 88 (MyD88) (35). The MyD88-dependent signaling pathway activates MAPKs, NF- $\kappa \mathrm{B}$, and activator protein-1 (AP-1). The up-regulation of c-Rel, RelB, p50, and p65 expression reflects a specific response of immature dendritic cells toward maturation-inducing cytokines. In addition to the Rel/NF- $\kappa \mathrm{B}$ factors, the activity of factors seems also to be involved in the differentiation of dendritic cells. Thus, the expression patterns of NF- $\kappa \mathrm{B}$ are additional markers for determining the maturation state of dendritic cells. Stimulating DCs with TLR ligands may result in activation of one or more MAPK signaling pathways leading to distinct DC responses. In contrast, inhibition of the MAPKs had the most significant effect on cytokine secretion for all TLR ligand-matured DCs with significant suppression for all cytokines observed. Therefore, MAPKs pathways mediate DC maturation and regulate the subsequent initiation and termination of immune responses. MSA has been shown to inhibit the NF- $\kappa \mathrm{B}$ and MAPKs pathway in DCs. The inhibitory action of immunosuppressive drugs on DC function has been associated 
with the Janus kinase 2 /signal transducer and transcriptional activator 4 (Jak2/Stat4) signaling pathway, $\mathrm{NF}-\kappa \mathrm{B}$, and MAPKs signaling $(36,37)$, suggesting that MSA's ability to inhibit the NF- $\kappa$ B and MAPKs signaling pathway could contribute to its inhibition of DC maturation.

Although the details of molecular mechanisms of MSA action in DC maturation has not been clarified yet, the data presented here suggest that MSA can inhibit phenotypic and functional maturation of DCs at cellular levels. The ability of MSA to inhibit DC functions may present an important cellular mechanism in its regulation of innate and adaptive immunity in inflammatory situations and in a tumor environment.

\section{Acknowledgment}

This work was supported by a Korea Science and Engineering Foundation (KOSEF) Grant funded by the Korea Government (MOST) (R13-2008-001-00000-00).

\section{References}

1 Grabbe S, Beissert S, Schwarz T, Granstein RD. Dendritic cells as initiators of tumor immune responses: a possible strategy for tumor immunotherapy? Immunol Today. 1995;16:117-121.

2 Lanzavecchia A. Identifying strategies for immune intervention. Science. 1993;260:937-944.

3 Schuler G, Steinman RM. Dendritic cells as adjuvants for immune-mediated resistance to tumors. J Exp Med. 1997;186: 1183-1187.

4 Sallusto F, Lanzavecchia A. Efficient presentation of soluble antigen by cultured human dendritic cells is maintained by granulocyte/macrophage colony-stimulating factor plus interleukin 4 and downregulated by tumor necrosis factor alpha. J Exp Med. 1994;179:1109-1118.

5 Sallusto F, Cella M, Danieli C, Lanzavecchia A. Dendritic cells use macropinocytosis and the mannose receptor to concentrate macromolecules in the major histocompatibility complex class II compartment: downregulation by cytokines and bacterial products. J Exp Med. 1995;182:389-400.

6 Neumann M, Fries H, Scheicher C, Keikavoussi P, Kolb-Maurer A, Brocker E, et al. Differential expression of Rel/NF-kappaB and octamer factors is a hallmark of the generation and maturation of dendritic cells. Blood. 2000;95:277-285.

7 Oyama T, Ran S, Ishida T, Nadaf S, Kerr L, Carbone DP, et al. Vascular endothelial growth factor affects dendritic cell maturation through the inhibition of nuclear factor-kappa B activation in hemopoietic progenitor cells. J Immunol. 1998;160:12241232.

8 Hehner SP, Heinrich M, Bork PM, Vogt M, Ratter F, Lehmann $\mathrm{V}$, et al. Sesquiterpene lactones specifically inhibit activation of NF-kappa B by preventing the degradation of I kappa B-alpha and I kappa B-beta. J Biol Chem. 1998;273:1288-1297.

9 Hehner SP, Hofmann TG, Droge W, Schmitz ML. The antiinflammatory sesquiterpene lactone parthenolide inhibits NFkappa B by targeting the I kappa B kinase complex. J Immunol.
1999;163:5617-5623.

10 Kwon OE, Lee HS, Lee SW, Chung MY, Bae KH, Rho MC, et al. Manassantin A and B isolated from Saururus chinensis inhibit TNF-alpha-induced cell adhesion molecule expression of human umbilical vein endothelial cells. Arch Pharm Res. 2005;28:55-60.

11 Seo CS, Lee YK, Kim YJ, Jung JS, Jahng Y, Chang HW, et al. Protective effect of lignans against sepsis from the roots of Saururus chinensis. Biol Pharm Bull. 2008;31:523-526.

12 Kim JY, Yoon YD, Ahn JM, Kang JS, Park SK, Lee K, et al. Angelan isolated from Angelica gigas Nakai induces dendritic cell maturation through toll-like receptor 4 . Int Immunopharmacol. 2007;7:78-87.

13 Han SB, Kim HM, Kim YH, Lee CW, Jang ES, Son KH, et al. T-cell specific immunosuppression by prodigiosin isolated from Serratia marcescens. Int J Immunopharmacol. 1998;20:1-13.

14 Dourado F, Madureira P, Carvalho V, Coelho R, Coimbra MA, Vilanova $\mathrm{M}$, et al. Purification, structure and immunobiological activity of an arabinan-rich pectic polysaccharide from the cell walls of Prunus dulcis seeds. Carbohydr Res. 2004;339:25552566.

15 Lehner MD, Morath S, Michelsen KS, Schumann RR, Hartung $\mathrm{T}$. Induction of cross-tolerance by lipopolysaccharide and highly purified lipoteichoic acid via different Toll-like receptors independent of paracrine mediators. J Immunol. 2001;166:51615167.

16 Yoon YD, Kang JS, Han SB, Park SK, Lee HS, Kang JS, et al. Activation of mitogen-activated protein kinases and AP-1 by polysaccharide isolated from the radix of Platycodon grandiflorum in RAW 264.7 cells. Int Immunopharmacol. 2004; 4:1477-1487.

17 Han SB, Moratz C, Huang NN, Kelsall B, Cho H, Shi CS, et al. Rgs1 and Gnai2 regulate the entrance of B lymphocytes into lymph nodes and B cell motility within lymph node follicles. Immunity. 2005;22:343-354.

18 Shlomchik WD, Couzens MS, Tang CB, McNiff J, Robert ME, Liu J, et al. Prevention of graft versus host disease by inactivation of host antigen-presenting cells. Science. 1999;285:412415.

19 Ozaki Y, Amakawa R, Ito T, Iwai H, Tajima K, Uehira K, et al. Alteration of peripheral blood dendritic cells in patients with primary Sjogren's syndrome. Arthritis Rheum. 2001;44:419431.

20 Vallin H, Perers A, Alm GV, Ronnblom L. Anti-double-stranded DNA antibodies and immunostimulatory plasmid DNA in combination mimic the endogenous IFN-alpha inducer in systemic lupus erythematosus. J Immunol. 1999;163:6306-6313.

21 Blanco P, Palucka AK, Gill M, Pascual V, Banchereau J. Induction of dendritic cell differentiation by IFN-alpha in systemic lupus erythematosus. Science. 2001;294:1540-1543.

22 Tajima K, Amakawa R, Ito T, Miyaji M, Takebayashi M, Fukuhara S. Immunomodulatory effects of cyclosporin A on human peripheral blood dendritic cell subsets. Immunology. 2003;108:321-328.

23 Xing N, ML LM, Bachman LA, McKean DJ, Kumar R, Griffin MD. Distinctive dendritic cell modulation by vitamin $\mathrm{D}(3)$ and glucocorticoid pathways. Biochem Biophys Res Commun. 2002; 297:645-652.

24 Lee JI, Ganster RW, Geller DA, Burckart GJ, Thomson AW, Lu L. Cyclosporine A inhibits the expression of costimulatory 
molecules on in vitro-generated dendritic cells: association with reduced nuclear translocation of nuclear factor kappa B. Transplantation. 1999;68:1255-1263.

25 Salgado CG, Nakamura K, Sugaya M, Tada Y, Asahina A, Fukuda $\mathrm{S}$, et al. Differential effects of cytokines and immunosuppressive drugs on $\mathrm{CD} 40, \mathrm{~B} 7-1$, and $\mathrm{B} 7-2$ expression on purified epidermal Langerhans cells1. J Invest Dermatol. 1999; 113:1021-1027.

26 Zhou LJ, Tedder TF. CD14+ blood monocytes can differentiate into functionally mature $\mathrm{CD} 83+$ dendritic cells. Proc Natl Acad Sci U S A. 1996;93:2588-2592.

27 Macatonia SE, Hosken NA, Litton M, Vieira P, Hsieh CS, Culpepper JA, et al. Dendritic cells produce IL-12 and direct the development of Th1 cells from naive CD4+ T cells. J Immunol. 1995;154:5071-5079.

28 Heufler C, Koch F, Stanzl U, Topar G, Wysocka M, Trinchieri $\mathrm{G}$, et al. Interleukin-12 is produced by dendritic cells and mediates $\mathrm{T}$ helper 1 development as well as interferon-gamma production by T helper 1 cells. Eur J Immunol. 1996;26:659668.

29 Grewal IS, Flavell RA. The role of CD40 ligand in costimulation and T-cell activation. Immunol Rev. 1996;153:85-106.

30 Gately MK, Renzetti LM, Magram J, Stern AS, Adorini L, Gubler $U$, et al. The interleukin-12/interleukin-12-receptor system: role in normal and pathologic immune responses. Annu
Rev Immunol. 1998;16:495-521.

31 Iwasaki A. Mucosal dendritic cells. Annu Rev Immunol. 2007; 25:381-418.

32 Klagge IM, Schneider-Schaulies S. Virus interactions with dendritic cells. J Gen Virol. 1999;80(Pt 4):823-833.

33 Fujii S, Liu K, Smith C, Bonito AJ, Steinman RM. The linkage of innate to adaptive immunity via maturing dendritic cells in vivo requires CD40 ligation in addition to antigen presentation and CD80/86 costimulation. J Exp Med. 2004;199:1607-1618.

34 Yoshimura S, Bondeson J, Foxwell BM, Brennan FM, Feldmann M. Effective antigen presentation by dendritic cells is NFkappaB dependent: coordinate regulation of $\mathrm{MHC}$, costimulatory molecules and cytokines. Int Immunol. 2001;13: 675-683.

35 Hirata N, Yanagawa Y, Ebihara T, Seya T, Uematsu S, Akira S, et al. Selective synergy in anti-inflammatory cytokine production upon cooperated signaling via TLR4 and TLR2 in murine conventional dendritic cells. Mol Immunol. 2008;45:2734-2742.

36 Hwang BY, Lee JH, Nam JB, Hong YS, Lee JJ. Lignans from Saururus chinensis inhibiting the transcription factor NFkappaB. Phytochemistry. 2003;64:765-771.

37 Yamamoto Y, Gaynor RB. Therapeutic potential of inhibition of the NF-kappaB pathway in the treatment of inflammation and cancer. J Clin Invest. 2001;107:135-142. 